\title{
Engaging with 'Caste’: Curriculum, Pedagogy and Reception
}

\section{Devika Mittal ${ }^{\dagger}$}

\section{Abstract}

Caste has been a persisting form of stratification that continues to evade equality and social justice in Indian society. Among the routes to tackle the menace of caste has been the education system. In this regard, the National Curriculum Framework 2005 came with a resolute to engage the students with different issues, including that of caste with a critical and empathic eye. This paper locates the challenges to this curriculum by focusing on the pedagogy and reception of the curriculum. In doing so, it argues that the challenges emanate from the social identities and lived realities of the students and the teachers.

Keywords: Caste; Education; Caste and Education; Caste-based Discrimination in Schools; National Curriculum Framework 2005; Caste in Modern India

\footnotetext{
${ }^{+}$Assistant Professor, Bharati College, Delhi University, E-mail: devikamittal31@gmail.com (C) 2020 Mittal. This is an Open Access article distributed under the terms of the Creative Commons Attribution License (http://creativecommons.org/licenses/by/2.0), which permits unrestricted use, distribution, and reproduction in any medium, provided the original work is properly cited.
} 


\section{Introduction}

Among the systems of stratification that pervades the Indian society is that of caste. Caste, argues Dumont (1999), divides the Indian society into 'a large number of hereditary groups, distinguished from one another and connected together by three characteristics: separation in matters of marriage and conduct; division of labour with each group having a profession from which their members can depart only within certain limits; and hierarchy which ranks certain groups as superior than others' (Dumont, 1999, pp. 21). The groups are broadly categorised into a four-fold classification system with Brahmans, Kshatriyas, Vaishyas and Shudras. A fifth category which falls outside the system is that of the Panchamas or people of the fifth order. A notion of purity and pollution underlies this stratification, with the Brahmans at the top of the hierarchy and the Panchamas at the lowest, considered to be "untouchables". The first three groups are regarded to be "upper caste". The fourth and the fifth group are considered to be "lower caste" (Bhattacharyya and Singh, 2018; Dumont, 1999).

While the caste system has its own existence as a social stratification system, it derives legacy in the form of a divine sanction from the Hindu religious order (Bhattacharyya and Singh, 2018; Dumont, 1999). Caste, however, transcends religious boundaries. There is substantial literature that establishes the prevalence of caste and caste-based prejudice in the social practices of other religious communities in India (Ahmad, 1962; Bhattacharyya and Singh, 2018; Dumont, 1999; Kannabiran and Kannabiran, 1991; Puri, 2003).

In contemporary India, there have been debates around the changing nature of the caste system. There are those who argue that the postindependence socio-political and economic landscape has significantly altered the caste system. Caste or more specifically, caste-based prejudice and inequality were among the critical concerns for the builders of the postindependence, modern India. This is reflected in the constituent assembly debates that approached the issue of caste from the angles of equity and social justice. Caste was also seen as a challenge in the crafting of a superseding national identity and for a composite nationalism that sought to uphold equality of religions, caste and ethnic groups (Pingle and Varshney, 2006, pp. 362). To tackle the menace of caste, there were policy initiatives that outlawed untouchability and introduced positive discrimination in the form of a quota system for the marginalised caste groups (Jaffrelot, 2010). There have also been political mobilisations by marginalised groups (Jaffrelot, 2010). Further, the market forces is argued to have been diluting the caste system, making class-based discrimination more rampant.

This over-emphasis on the changing reality, however, needs questioning, argues Dirks (2001) and Dumont (1999), among others. Caste also cannot be assumed to have lost its importance in the face of the new economic forces. Jodhka's work in the corporate sector shows how caste identity continues to hold ground even in a market based on merit (Jodhka, 2008). While there have been changing forces, caste continues to be a defining institution of inequality in Indian society. There are, however, differing and even contradictory views about its status, which also undermine the efforts to tackle the evil of caste.

This study examines one such effort of a statemandated school curriculum to address castebased inequalities. The research emerged out of my doctoral research on the popular discourse on secularism in the Indian context. This has been studied through an ethnographic study of a government-aided school in Delhi for a duration that spanned about 11 months in the years 2015-16. The study is structured, to begin with a detailed description of the objective and content of the National Curriculum Framework 2005. It then moves on to examine the different ways in which the students engage with the content. The contents examined are from the textbooks: 
- NCERT (2006). Social and Political Life - I: Textbook in Social Sciences for Class VI. (SP-I)

- NCERT (2006). Social and Political Life - II: Textbook in Social Sciences for Class VII. (SP-II)

- NCERT (2006). Social and Political Life III: Textbook in Social Sciences for Class VIII. (SP-III)

- NCERT (2006). Democratic Politics - I: Textbook in Social Sciences for Class IX. (DP-I)

- NCERT (2006). Democratic Politics - II: Textbook in Social Sciences for Class $X$. (DP-II)

In the subsequent section, the paper also focuses on the pedagogy, reflecting on teachers as the bridge between the text and the students. The study tries to capture how teachers make sense of the curriculum and how their identity and interest influences their pedagogy. While reflecting on the design and the transaction of the curriculum, the study engages with how caste is being understood in contemporary India.

\section{'Caste' in the National Curriculum}

Education, as Advani (2009) among others argue, holds much importance in the nationbuilding project in the Indian context (Advani, 2009, pp. 56). This explains the persistent state interventions in the form of laws and policies to structure and restructure the education system. The objective of education was to nurture students or citizens of a united country who would have faith in the constitutional ideals and will work for the development of the country. This was integral not just for a country that was ethnically so diverse, but it was also essential in a society that was inherently so unequal. The differences, as well as the inequalities arising out of caste and community, received importance in this project.

There has been a close association between caste and education in India. Some castes have traditionally had a virtual monopoly over education while excluding others. The notion of purity and pollution underlying the caste system also helped maintain this order. Modern education, however, strived to alter this set-up, as Beteille (2006, pp. 174) rightly points out, 'it was unthinkable for Brahmins (the so-called upper caste) and Dalit (the so-called lower caste) children to even sit together'. Beteille regard schools in post-independence India to be one of the few public places where caste-based inequality and discrimination could be defied (Beteille, 2006, pp. 174). While there exist reports and studies of schools, especially those located in the rural areas, that reveal discriminatory attitudes and practices towards students of the oppressed caste groups, these incidents are seen as an impediment to achiev[ing] the constitutional ideals and provisions (Sharma, 2016, pp. xvi).

In its objective to improve the education system to make it more 'effective' in forming and embedding the national imagination, the curriculum has also held been an eminent site for constant debates and deliberations. Amidst these deliberations, emerged the National Curriculum Framework 2005 (hereafter, NCF 2005). While NCF 2005 reiterates the aim of education to inculcate faith and commitment to the 'chosen ideals and principles' like its predecessors, for Kumar (2012), NCF 2005 represents a 'paradigmatic change in the educational landscape' (Kumar, 2012, pp. 22). The books presented themselves to be starkly different from the previous books. The preliminary pages of these new textbooks stress on how the books strive for a more dialogical approach to education. For this, the chapters, especially those in the social science subjects, are also organised and structured to reflect this approach, with section headings in the form of questions, the chapters full of political cartoons, photo essays, in-text and end-text questions. These news books are a contrast to the previous books which as Madan (2003) and Jain (2004) argue familiarise the students about the political system, the rights and duties of the citizens in an ideal way. The old books tend to engage with the issues of caste, gender and class as abstract entities.

On the contrary, the new textbooks explicitly declare their aim to promote critical thinking, to help the students to bridge the gap between the 
text and the real world. For Menon and Banerjee (2018), the NCF 2005 understood child as 'natural learner' and tried to understand how the child learns, situating 'the child in contexts' (Menon and Banerjee, 2018, pp. 216). The new books strive to help students comprehend knowledge that they find in different contexts, and to guide their actions, inspire them to change the world around them.

\section{Analysis of the Textbooks}

Coming to our specific focus, the new curriculum engages with community and caste in different grade levels. In the grade 6 textbook 'Social and Political Life $-I$ ' (SP $-I)$, the second chapter titled 'Diversity and Discrimination' initiate the discussion on caste as a form of inequality and discrimination. The chapter introduces the caste system as a division of labour that not only hierarchises work but associates with the differing kinds of jobs, a differential degree of social esteem and the notion of purity and pollution. To illustrate, the chapter gives examples of oppressive practices in the past. The chapter reads, 'Caste rules were set which did not allow the so-called "untouchable" to take on work, other than what they were meant to do. For example, some groups were forced to pick garbage and remove dead animals from the village. However, they were not allowed to enter the homes of the upper castes or take water from the village well, or even temples. Their children could not sit next to children of other castes in school' (SP - I, 2006, pp. 19). The chapter then goes on to give a detailed narrative that traces the life and struggle of B.R. Ambedkar, an eminent Dalit Icon and a visionary of Modern India. There is a debate around the term 'Dalit' which literally means "broken/scattered". While some use the term only for the scheduled caste community in India, several others regard it as an umbrella term that would also include Scheduled Tribes (ST) and Other Backward Classes (OBCs) (Shah 2001: 18; see also, Bhattacharyya and Singh, 2018). Shah (2001) explains this by arguing that in the popular and intellectual discourse, the term Dalit is seen not just as a caste but as a symbol of change and revolution (Shah 2001: 22-23). In this paper, the term Dalit is being used to refer to the Scheduled Castes. The chapter argues that the constitution of the modern, free India outlaws caste-based discrimination and guarantee equal rights, yet it also acknowledges that equality is still to be achieved. The chapter ends with, 'Though these ideals are enshrined in our constitution, this chapter points out that inequalities exist even today' (SP - I, 2006, pp. 23).

The textbooks of class VII and VIII also continue the discussion on caste-based discrimination as an enduring challenge in post-independence India. The chapter I titled 'Equality in Indian Democracy' of class VII textbook 'Social and Political Life II' (SP - II) shows how caste has been an important social identity that one grows up with. The text reads, 'If you live in rural India, your caste identity is something that you probably learned or experienced very young'. The chapter also dismisses the idea that caste identity is crucial only in the rural area. It states, 'If you live in urban India, some of you might think that people no longer believe in caste. However, just look at the matrimonials shown from a leading English newspaper, and you will see how important the issue of caste continues to be in the minds of higher educated urban Indians' (SP - II, 2006, pp. 7).

Similarly, the class VIII 'Social and Political Life III' (SP - III) textbook also brings together stories and experiences of Dalit exploitation, especially in terms of ritual impurity. There is also a special section on manual scavenging which points out that while it is banned, it is still practised in different parts of the country. The textbook also introduces affirmative action in the form of the reservation system though it only talks about the reservation for the Scheduled Castes (SC) and Scheduled Tribes (ST) groups. The Scheduled Castes and Scheduled Tribes are the constitutional terms that refer to communities that are socially and economically disadvantaged. The Scheduled Castes includes caste communities which have been placed in the fifth category or the panchamas who are the most downtrodden in the caste hierarchy (Michael, 2007, pp. 16). The textbook places 
affirmative action as an approach to equality, as positive discrimination. Resting it on the long history of marginalisation and discrimination that prevented the Dalits to progress, the affirmative action in the form of the reservation is shown as a medium to ensure equality and social justice.

In class IX, with the discussion ought to be more elaborate and engaging, an aspect of the approach to caste is introduced in chapter 4 titled 'Working of Institutions'. As the chapter delves in to explain the decision-making process in India, it takes the example of the Other Backward Classes (OBC) reservation. The chapter elaborates on how the decision around the reservation for the $O B C$ was made and identifies the different institutions like the Government and the Supreme Court that were involved in this decision-making. The chapter notes that despite protests against the $\mathrm{OBC}$ reservation, the reservation was upheld by the Supreme Court and implemented by the Government. The reason is stated in the next chapter. The text in Democratic Politics - I (DP-I) reads:

The Government of India has provided reservations for Scheduled Castes, Scheduled Tribes and Other Backward Classes. Various governments have different schemes for giving preference to women, poor or physically handicapped in some kinds of jobs. Are these reservations against the right to equality? They are not. For equality does not mean giving everyone the same treatment, no matter what they need. Equality means giving everyone an equal opportunity to achieve whatever one is capable of. Sometimes it is necessary to give special treatment to someone in order to ensure equal opportunity. This is what job reservations do (DP-I, 2006, pp. 80).

The class $X$ textbook titled Democratic Politics II (DP-II), while reiterating the persistence of castebased inequalities, introduces some other aspects of the caste issue, including the overlapping of caste and class. The text makes use of the statistics to make the point:
The caste groups that had access to education under the old system have done very well in acquiring modern education as well. Those groups that did not have access to education or were prohibited from acquiring it have naturally lagged behind. That is why there is a disproportionately large presence of 'upper caste' among the urban middle classes in our country. Caste continues to be closely linked to economic status. (DP-II, 2006, pp. 13)

The chapter also discusses another aspect of the contemporary situation that of the caste-based political assertions and caste-based vote bank politics. While caste is also discussed in the curriculum of class XI and XII, since the school understudy does not offer humanities, this study will limit itself to what is taught in the school.

The curriculum, as we see, not just educate but sensitise students about caste as a menace in society. Through the text, in-text questions, photo essays and activities in the chapters, the curriculum designers sought to seek empathy, inspire students to imagine and think of what they should do to eliminate caste. There are, however, some limitations and gaps that we can see in the content of the curriculum itself. The curriculum does not focus sufficiently on OBCs. This is crucial as we will note through the students' voices in the subsequent section that the popular discourse on caste and caste-related issues is often modeled on the opinion around the OBCs. The curriculum also does not address another critical issue that appears in the debate on the reservation system that is of intergenerational mobility.

While as we see, the curriculum strives to address an essential issue in the society and approaches different aspects of it, with the hope that students will develop their understanding and guides their action based on the curriculum, the curriculum, however, does not produce knowledge by itself. It is imperative to understand how the text is transmitted and received. 
Engaging with the Curriculum: Students' Understanding of 'Caste'

The first thing to note as we move to understand the relationship between the text and the environment in which the former speaks, is the hierarchy of subjects constructed or maintained by the students. Neha and Preeti (names changed) study in class VII. Civics is not their choice of subject. Talking about their interests, they express their passion for watching latest Hindi movies. They, however, make it clear that they do not like serious or issue-based movies. I asked them about caste-based discrimination, to which Neha says, 'Yes in earlier times, people used to discriminate on the basis of caste. People of Scheduled castes and Scheduled tribes were badly treated'. When asked if it still persists, they both state that there is no caste-based discrimination in contemporary society. They attribute their knowledge to the books. This is interesting as, as we had noted in the previous section, the curriculum does talk about caste in post-independence India, yet the students attribute it as a practice of the past.

They, however, are not alone in doing so. Table 1 is a demonstration of the evidence. Table 1 is based on a questionnaire that was circulated among students of class IX. The data gives an insight into the student's reception of the curriculum and their understanding of castebased inequalities.

\begin{tabular}{l|l|l}
\hline \multicolumn{2}{c}{ Table 1: Students' Opinion about Caste-Based Discrimination } \\
\hline Opinion about Caste-based Discrimination & Number & Percentage \\
\hline $\begin{array}{l}\text { Caste-based discrimination does not exist in } \\
\text { contemporary society }\end{array}$ & 38 & $\mathbf{4 4 . 1 9 \%}$ \\
\hline Caste-based discrimination still exists & 20 & $\mathbf{2 3 . 2 6 \%}$ \\
\hline Mixed caste with religion-based discrimination & 15 & $\mathbf{1 7 . 4 4 \%}$ \\
\hline Equated caste with class-based discrimination & 5 & $\mathbf{5 . 8 1 \%}$ \\
\hline Talked about gender-based discrimination & 4 & $4.65 \%$ \\
No response & 4 & $\mathbf{4 . 6 5 \%}$ \\
\hline Total & 86 & $\mathbf{1 0 0 \%}$ \\
\hline Source: From the Field Study & &
\end{tabular}

As we note from Table 1, in the sample of 86 students from class IX, 38 students deny the prevalence of caste-based discrimination in society. They talk about caste as an outlawed practice that existed in the past. A student writes about caste as a practice of the past and denies witnessing it in contemporary society, at least in urban cities like Delhi. Another student reiterates the notion of caste being abstract and distant reality:

Yes, there is caste-based discrimination. Earlier, there was much discrimination against Dalits, but now it has reduced. Today, it is practised mostly in villages.

In doing so, the students contrast with the content of the textbooks that point out the persistence of caste-based inequalities and discrimination in modern and urban India.
Twenty students opine that there is caste discrimination. Some students even regard it as their everyday, lived reality. A student asserts:

There is caste discrimination in our society. People discriminate in different ways. There is discrimination between black and white and between upper caste and lower caste.

Some talk about discrimination, the practices that draw from the book but go beyond it. A student remarks:

Yes, there is caste discrimination in India. In the past, there is vast discrimination against Dalits, but today this has reduced. Today this has ended in some places, but in some places, discrimination still exists. Like in schools, societies (housing) or other places, if there is any person from Gujjar caste, then there is 
definitely discrimination. Gujjars scare other people and create difficulties for them, especially for students.

The school draws student population from diverse ethnic communities, including the Gujjar community. From informal conversations with students and staff also, it emerges that some of the Gujjar students do try to dominate over students of other communities. So the student may be referring to his own school and his own reality that he/she probably encounters every day in and beyond the school.

Some students deny caste discrimination and instead talk about caste-based reservations. According to a student:

In the 19th Century, there was caste discrimination but not today in the 21st Century. There is no caste system now. Nevertheless, we have a reservation system. Why do we need it now?'

Many students speak against the reservation, not to uphold caste identity and norms to govern access to education and jobs but to uphold 'merit'. In doing so, they oppose the understanding that the textbooks offer. They do not accept the argument that the class VIII textbook gave for affirmative action, regarding it as a step towards equality and social justice. While this data is from students of class IX who at the time of the questionnaire had interacted with chapters till class VIII, students of higher classes who have studied the chapters on caste that show the correlation of caste and class, also object to a caste-based reservation, seeing it as a 'new form of caste system'.

As we see, there are different engagements with the discursive knowledge on caste being produced through the official curriculum. While some students experience caste as a form of discrimination in their school and everyday life, some understand it to be an evil that somehow still remains somewhere in certain parts of the country but away from them. For some others, caste is only observable through caste-based politics. These differing views emanate from their own caste identities and social upbringing.
The students are engaging with the knowledge they receive based on their own social positioning, their everyday world and engagement with different sources of knowledge, school and curriculum being only one of them. In fact, in their discussion on how NCF 2005 can be made more effective, George and Madan (2009) also emphasise on the role of parents - recognising that parents need to be resource person who has experienced, read and heard about the social, political and economic events happening around the child. For, it is the family that provides the primary socialisation of children that helps them make sense of themselves and the world around them. The students, thus, have to be understood, as Bernstein (1975) stresses, in a complex manner. Bernstein argues that the students are affected by several factors, including the family, his/her social background, level of maturity and friendship network.

Other theorists and ethnographies have also established this active engagement of students with the knowledge they receive on schooling. The school is, after all a lively institution that, Thapan (2006) notes, is constructed by the teachers, the pupils and their complex relationship (Thapan, 2006, pp. 4). To understand the pedagogic process, it is crucial to understand the complex and subjective meanings which teachers and pupils attach to or perceive in their actions. It is essential to understand the pupil and teacher culture (Thapan, 2006, pp. 4). The process of transmission of knowledge can be understood as, what Thapan (2006) argues, a 'pedagogic encounter' which is a communication, an engagement between the teachers and the students, their everyday worlds.

While the students make sense of the curriculum as the recipients, so do the teachers or those who bring the curriculum alive. As the teachers teach, they engage with the curriculum and the form of engagement with the curriculum may also differ among the teachers.

\section{Teachers on teaching 'Caste'}

Like the taught, those who teach may also have varying understandings of the knowledge that 
they are expected to transmit. It is, thus, equally important to focus on the teachers, their understanding and the way they transact the knowledge from the books. Teachers are, after all, the bridge between the text and the student. While discussing about the NCF 2005, the importance of the teacher and the school culture has been emphasised by Batra (2005), Mehrotra (2007), George and Madan (2009) among several others.

While Mehrotra (2007) regards the new NCF books to be well-equipped to initiate critical thinking in students, she emphasises on the need for teachers' training. This is also echoed by Alex M. George and Amman Madan (2009, pp. 14) who are of the opinion that "it is not enough for teachers to possess lots of information", but they must think actively on these topics (George and Madan, 2009, pp. 14). The teachers are required to understand the importance and to encourage the students to engage with the text. In her work, Thapan (2014) shows the importance of the same. She cites an example wherein a teacher is teaching students about secularism, but when a student questions her about the 'privileged' status given to the minorities, the teacher does not clear the misconceptions of the student in an adequate manner (Thapan, 2014, pp. 167). The teachers of the school who vary in their socio-economic background, perceptions about knowledge, teaching and contemporary issue are united in talking about the difficulty with these new books. The social science teachers share that while they find new books to be much more interesting, they come with their own set of problems. Kartik (name changed), one of the social science teachers, shares:

While the books are good, they are talking about issues which are important. They also create problems as they make students aware of their and other's caste identity.

He shares instances wherein when students read about the practices of another community or even about the discrimination meted out to a particular community, they may call out to their classmates who belong to those communities:
Look, what this says about you!' (Dekh tere bare mein kya likha hua hai) or 'See they are writing about you people!' (Tum logo ke bare mein likha hua hai) are common comments that Kartik says he hears in his classroom.

For him, this visibility to caste structures and discriminations through the curriculum can have unintended implications as it produces stereotypes and can victimise students who belong to the marginalised group.

His concern also reflects the pedagogical dilemmas associated, in this case with how to teach this curriculum in a society which is so caste-conscious and divided but which often get ignored, unattended in the education system which rarely consults the teachers, as several teachers in the school often argue. There are also, however, differing opinions on these new books. Kriti (name changed), another social science teacher, finds the new books interesting from which she herself gets to learn a lot. She asserts:

These new books generate much discussion in class. Students have many questions and even share their own experiences. It does make the class very lively. I myself get to learn so much.

She acknowledges that students also surface many stereotypes but then:

I explain, give examples, try to convince, even if on some issues (she says this for the reservation), I myself may disagree with the book. The teacher has to address these issues himself/herself", she says.

It is imperative to note the difference in the views of the two teachers who seem to draw from their own social positions. Kartik is from Gujjar community which has engaged in the caste-based political mobilisation and is classified in the OBC community in some states. Kriti is from an upper-caste background. While both Kartik and Kriti acknowledge the challenges in the form of stereotypes that students may exhibit, Kartik is more conscious and gives the disagreements and the behaviour of the student 
more weightage. The teachers, as we see, are not a homogeneous group, their social identities, motivations and intentions have a varying influence on them. These orientations also affect the nature and content of their teaching processes.

\section{Conclusion}

The study highlighted the differing perceptions and realities around caste in contemporary India by reflecting on the constraints to an educational initiative that sought to address caste-based inequalities. The research studied a statemandated school curriculum, the NCF 2005 that came with a promise to engage the students or the recipients of the curriculum with issues of social inequality and inspire them to take action to tackle them.

The challenge emerges in the transaction of the curriculum. In the process of the transaction of this knowledge, the text interacts with the everyday worlds of the students. We note a multiplicity of ideas around caste that not only emerges from but also sharply contrasts with the text. The students have varying understandings of caste in modern society. While some students claim to experience caste on a daily basis, others engage with it as a concept in their book. While for some, caste-based identity is an old source of discrimination and inequality, for some other students, it is a new source of discrimination that privileges identity over merit.

From the point of view of understanding school education, in highlighting these varying responses to the curriculum, the study also highlights the need to see students in their social contexts that they may use to alter or subvert the knowledge they receive in the curriculum. Indeed, the study points out a need to focus on the pedagogy and the pedagogues as we note that the way the text is transacted depends on the social identity, interest and motivation of the teacher or the pedagogue. We note that not only the students but the teachers also make sense of the text and the discussion that it may generate according to their own social identity. The study, thus, argues that in order to make a curriculum or a policy effective, it is imperative to look at the actors that may influence and direct its impact.

\section{References}

Advani, S. (2009). Schooling the National Imagination. New Delhi: Oxford University Press.

Ahmad, Z. (1962). Muslim Caste in Uttar Pradesh. Economic and Political Weekly, 14(7), 325-336.

Batra, P. (2005). Voice and Agency of Teachers: Missing Link in National Curriculum Framework. Economic and Political Weekly, 40 (40), 43474356.

Bernstein, B. (1975). Class, Codes and Control: Volume III Towards a Theory of Educational Transmission. London \& New York: Routledge.

Beteille, A. (2006). The School as an Institution. In: A. Sethi, R. Kumar and S. Sikka, ed., School, Society, Nation: Popular Essays in Education. New Delhi: Orient Longman, 166-178.

Bhattacharyya, R. and Singh, S. (2018).

Exclusion (and seclusion): Geographies of Disowned Widows of India, GeoJournal, 83 (4), 757-774, DOI: 10.1007/s10708-017-9800-0.

Dirks, N. (2001). Castes of Mind: Colonialism and the Making of Modern India. UK: Princeton.

Dumont, L. (1999). Homo Hierarchicus: The Caste System and its Implications. India: Oxford University Press.

George, A. and Madan, A. (2009). Teaching Social Science in School: NCERT's New Textbook Initiative. New Delhi: Sage Publications.

Jaffrelot, C. (2010). Religion, Caste and Politics in India. India: Primus Books.

Jain, M. (2004). Civics, Citizens and Human Rights: Civics Discourse in India. Contemporary Education Dialogue, 1(2), 165-198. https://doi.org/10.1177/097318490400100203. Kannabiran, V. and Kannabiran, K. (1991). Caste and Gender: Understanding Dynamics of Power and Violence. Economic and Political Weekly, 26 (37), 2130-2133.

Kumar, A. (2012). Indian Social Studies Curriculum in Transition: Effects of a Paradigm Shift in Curriculum Discourse. Transnational Curriculum Inquiry, 9(1), 20-53. 
Madan, A. (2003). Old and New Dilemmas in Indian Civic Education. Economic and Political Weekly, 38(44), 4655-4660.

Mehrotra, D. (2007). Texts and Contexts, Seminar. Retrieved on 13 December 2008 from, http://www.indiaseminar.com/2007/569/569_deepti_priya_meh rotra.htm.

Menon, S. and Banerjee, R. (2018), Construction of children in Indian educational curricular and policy documents (1964-2005): Implications for education. In: T. Saraswathi, S. Menon, S. and A. Madan, (Ed.), Childhoods in India: Traditions, Trends and Transformations. New York: Routledge, 205-228.

Michael, S.M. (2007) Dalits in Modern India: Vision and Values. New Delhi: Sage Publications. NCERT (2006). Social and Political Life - I: Textbook in Social Sciences for Class VI. NCERT (2006). Social and Political Life - II: Textbook in Social Sciences for Class VII.

NCERT (2006). Social and Political Life - III: Textbook in Social Sciences for Class VIII.

NCERT (2006). Democratic Politics - I: Textbook in Social Sciences for Class IX.
NCERT (2006). Democratic Politics - II: Textbook in Social Sciences for Class $X$.

Pankaj, A. (2007). Engaging with discourse on caste, class and politics in India. South Asia Research, 27(3), 333-353. https://doi.org/10.1177/026272800702700305

Pingle, V. and Varshney, A. (2006). India's Identity Politics: Then and Now. In: D. A. Kelly, R. S. Rajan, and G. H. L. Goh, (Ed.), Managing Globalisation: Lessons from China and India, Singapore: World Scientific Book Corporation, 353-386.

Puri, H. K. (2003). The Scheduled Caste in the Sikh Community - A Historical Perspective. Economic and Political Weekly, 38 (26), 26932712.

Shah, G. (2001). Dalit Identity and Politics. New Delhi: Sage Publications.

Sharma, A. (2016). School Worlds: An Ethnographic Study. New Delhi: Sage Publications.

Thapan, M. (2006). Life at School: An Ethnographic study. New Delhi: Oxford University Press.

Thapan, M. (2014). Ethnographies of Schooling in Contemporary India. New Delhi: Sage Publications. 